\title{
Production and Characterization of Monoclonal Antibodies against Human Ceruloplasmin
}

\author{
Won Sik Eum, Hee Soon Choi, Dae Won Kim, Sang Ho Jang, Soo Hyun Choi, So Young Kim, \\ Jinseu Park, Jung Hoon Kang ${ }^{\dagger}$, Sung-Woo Cho \\ Ki-Yeon Yoo", Tae-Cheon Kang", Moo Ho Won"** and Soo Young Choi* \\ Department of Genetic Engineering and Research Institute for Bioscience and Biotechnology, Hallym University, \\ Chunchon 200-702, Korea \\ 'Department of Genetic Engineering, Cheongju University, Cheongju 360-764, Korea \\ Department of Biochemistry and Molecular Biology, University of Ulsan College of Medicine, Seoul 138-736, Korea \\ ${ }^{\S}$ Department of Biochemistry, Kyungpook National University, Taegu 702-701, Korea \\ "Department of Anatomy, College of Medicine, Hallym University, Chunchon 200-702, Korea
}

Received 19 June 2004, Accepted 10 September 2004

Ceruloplasmin (CP) is the major plasma antioxidant and copper transport protein. Monoclonal antibodies (mAbs) against human $\mathrm{CP}$ were produced and characterized. A total of five hybridoma cell lines were established (CP2, CP10, CP20, CP25, CP30). From the epitope mapping analysis, two subgroups of $\mathrm{mAbs}$ recognize different peptide fragments were identified. When the purified CP was incubated with the mAbs, the ferroxidase activity of CP was inhibited up to a maximum 57\%. Immunoblotting with various tissue homogenates indicated that all the mAbs specifically recognize a single protein band of $130 \mathrm{kDa}$. They also appear to be extensively cross-reactive among different mammalian including human and avian sources. These results demonstrated that only one type of immunologically similar $\mathrm{CP}$ is present in all of the mammalian tissues including human. The CP mAbs could be of great benefit to design the diagnostic kit for $\mathrm{CP}$ related diseases such as Wilson's disease.

Keywords: Antioxidants, Human ceruloplasmin, Monoclonal antibodies

\section{Introduction}

The blue oxidase ceruloplasmin (CP), which has a molecular weight of 132,000 and contains 6 copper atoms per molecule

*To whom correspondence should be addressed.

Tel: 82-33-248-2112; Fax: 82-33-241-1463

E-mail: sychoi@hallym.ac.kr; mhwon@hallym.ac.kr and $7-8 \%$ carbohydrate, plays a role in cardiovascular function exerting a beneficial influence on cardiovascular health (Mateescu et al., 1995; Osaki et al., 1966; Richardson, 1999; Aouffen et al., 2001; Kang et al., 2002).

Since the generation of oxidation products, including $\mathrm{O}_{2}^{-}$ and $\mathrm{H}_{2} \mathrm{O}_{2}$, is associated with conditions that increase plasma $\mathrm{CP}$, which can serve as a scavenger of superoxide radicals, the functional properties of $\mathrm{CP}$ in vitro have led to suggestions that it serves as a serum antioxidant in vivo (Osaki et al., 1966; Aouffen et al., 2001). Furthermore, CP activity increases during inflammation, infection, and injury, suggesting that serum $\mathrm{CP}$ acts possibly as an antioxidant and as an acute phase protein (Gitlin, 1988; Fleming et al., 1991). During exposure to oxidative stress, it has been implicated that substantial CP inactivation may occur and free copper ions could be released (Swain et al., 1994; Eum and Kang, 1999; Choi et al., 2000). Therefore, damaged CP may cause the augmentation of free radical-mediated damage to other macromolecules upon exposure to oxidative stress.

Low levels of serum CP have been observed in neonates, cases of nutritional copper deficiency, Menkes disease, toxic milk mice, and severe liver diseases as well as Wilson diseases (Scheinberg and Steinlieb, 1984; Danks, 1989). In Wilson disease the absence of impaired function of a copper transporting ATPase disrupts copper movement into the secretory pathway, resulting in the decreased serum CP observed in affected patients (Culotta and Gitlin, 2001). Despite the essential roles of $\mathrm{CP}$ in various diseases, the structural and regulatory studies are not sufficiently investigated yet. Therefore, in the present study, the monoclonal antibodies against human $\mathrm{CP}$ has been produced and characterized for the first time and it would be useful tool 
for the structural studies of CP and develop the diagnostic kit for $\mathrm{CP}$ related diseases.

\section{Materials and Methods}

Materials Human plasma CP was purchased from Calbiochem (San Diego, USA). Bovine serum albumin, 2-mercaptoethanol, and goat anti-mouse IgG conjugated with horseradish peroxidase (HRP) were purchased from Sigma Chemical Co. (St. Louis, USA). Chelex 100 was purchased from Bio-Rad Lab Inc (Hercules, USA). Dulbecco's Modified Eagle's (DME) medium, hypoxanthineaminopterin-thymidine (HAT), fetal bovine serum (FBS), and penicillin/streptomycin antibiotics were purchased from GIBCO BRL (Grand Island, USA). Goat anti-mouse IgG conjugated with alkaline phosphatase (AP) was obtained from Santa Cruz Biotechnology, Inc. (Santa Cruz, USA). Superose 6, Hybond-C ${ }^{+}$ nitrocellulose membrane and ECL Western blotting detection reagent were purchased from Amersham Phamacia Biotech Inc. (Piscataway, USA). All chemicals were of the highest purity obtainable.

Purification of CP The commercial CP was chromatographed on Superose 6 FPLC column to remove the salts and small fragments. All of the solutions that were used in these experiments were treated with Chelex 100.

Production of anti-human CP monoclonal antibodies For injection, the purified CP $(100 \mu \mathrm{g}$ in a volume of $200 \mu \mathrm{l})$ was mixed with an equal volume of Complete Freund's Adjuvant by sonication for three 15 -sec bursts at $30 \%$ maximum intensity. The antigen-adjuvant mixture was injected into a female 6 week old $\mathrm{BALB} / \mathrm{c}$ mouse intraperitoneally. The first injection was followed by 3 booster injections at 3- to 4 -week intervals. The final injection was given 3 or 4 days before the cell fusion, without adjuvant. The feeder-layer cells were prepared 1 day before fusion. The BALB/c mouse (12-18 weeks old) was killed by cervical dislocation and its abdominal skin was carefully removed. Five milliliters of ice-cold $11.6 \%$ sucrose solution was injected into the peritoneal cavity. About $3 \mathrm{ml}$ of the injected solution were pulled out, and peritoneal cells were collected by centrifugation for $5 \mathrm{~min}$ at $650 \times \mathrm{g}$. The fusion experiments were performed as follows (Choi et al., 1995; 1996). In brief, spleen cells released by tearing the removed spleen with fine forceps were collected in a $15 \mathrm{ml}$ centrifuge tube. Next, the prepared spleen cells and SP2/o-Ag-14 mouse myeloma cells (Shulman et al., 1978) were combined, and $1 \mathrm{ml}$ of $50 \%$ polyethyleneglycol 1,500 in DME (serum-free) was slowly added. The fusion process was allowed to continue for $90 \mathrm{sec}$ at $37^{\circ} \mathrm{C}$, and then it was stopped by adding DME. To avoid osmotic shock, $1 \mathrm{ml}$ of DME was added slowly for the first $1 \mathrm{~min}$, and $2 \mathrm{ml}$ of DME was added for the next $1 \mathrm{~min}$. Over a period of $10 \mathrm{~min}$, a total of 20 $\mathrm{ml}$ of DME was added. Cells were collected by centrifugation for 1 min at $650 \times g$, suspended in $20 \mathrm{ml}$ of selective HAT medium (DME supplemented with 20\% FBS, antibiotics, and HAT) carefully by swirling, and then centrifuged for $1 \mathrm{~min}$ at $650 \times g$. The cells were resuspended in $120 \mathrm{ml}$ of HAT medium, and then 1 $\mathrm{ml}$ of the cell suspension was transferred into each well of five 24well plates.
About 2 weeks after the fusion, culture supernatants were collected and first screened by immunodot-blot analysis with purified enzyme as an antigen, and then by Western blot analysis. Positive clones selected by the screening methods were transferred to 6-well plates, grown in tissue culture flasks $\left(75 \mathrm{~cm}^{2}\right)$, and frozen in a liquid-nitrogen tank. All the positive clones were frozen first and then cloned by limiting the dilution after thawing. In order to clone a single, specific antibody-secreting cell, aliquots of the cultured cells were diluted in a fresh DME medium and counted using a haemocytometer. The samples to be cloned were diluted in an HT medium to 15 cells $/ \mathrm{ml}$. Seventy $\mu \mathrm{l}$ of the well-suspended sample was plated in each well of a 96-well plate to which $140 \mu \mathrm{l}$ of fresh HT media was added. The cloned samples were fed 2 drops of medium on day 5 and day 12. The cells of each well were expanded and re-assayed by immuno-blotting analysis.

Immuno-blotting analysis For immuno-blotting, the proteins separated by SDS-polyacrylamide gel electrophoresis (SDS-PAGE) were electrophoretically transferred to nitrocellulose membrane and the membranes were rinsed briefly in distilled water and then airdried (Lee et al., 2002; Lee et al., 2003). The blots were blocked with Blotto [2\% nonfat dry milk in Tris-buffered saline (TBS)] for $1 \mathrm{~h}$ at $37^{\circ} \mathrm{C}$. After rinsing with TBS, the blots were incubated in culture supernatants for $1 \mathrm{~h}$ and washed 3 times in TBS containing Tween 20 at $5 \mathrm{~min}$ intervals. Then, the membrane was incubated for $1 \mathrm{~h}$ at $37^{\circ} \mathrm{C}$ with horseradish peroxidase conjugated goat anti-mouse IgG antibodies, diluted $1: 5,000$ in TBS containing $0.05 \%$ Tween20. Finally, the bound conjugate was identified by incubation of the membrane in substrate buffer $(0.5 \mathrm{mg} / \mathrm{ml}$ 4-chloro-1-naphthol in $1: 5 \mathrm{v} / \mathrm{v}$ methanol/TBS and $0.015 \% \mathrm{H}_{2} \mathrm{O}_{2}$ ) for $5 \mathrm{~min}$ at room temperature.

Purification of monoclonal antibodies For purification of $\mathrm{mAbs}, 100 \mathrm{ml}$ of the culture supernatant was centrifuged for $30 \mathrm{~min}$ at $15,000 \times g$ to clarify cells and insoluble aggregates, and then applied onto a protein A-agarose column (packed volume, $1 \mathrm{ml}$; Sigma). The column was washed with phosphate-buffered saline (PBS) until the absorbance of unbound proteins came down to the background level, and then the antibodies were eluted with $0.1 \mathrm{M}$ glycine- $\mathrm{HCl}(\mathrm{pH} 2.5)$. Adding of $1 \mathrm{M}$ Tris neutralized the eluted antibodies, and then they were dialyzed against PBS.

Determination of monoclonal antibody isotype For isotyping, purified mAb was diluted with PBS $(1: 20,000)$ and the sample was determinate with the IsoStrip mouse mAb isotyping kit (Roche Molecular Biochemicals, Indianapolis, USA).

Epitope mapping One-dimensional epitope mapping was carried out according to a procedure previously described (Choi et al., 1995;1996). Ten micrograms of purified CP in SDS sample buffer were mixed with an equal volume of Staphylococcus aureus V-8 protease solution $(0.5 \mu \mathrm{g}$ in SDS sample buffer). The mixtures were applied onto a SDS polyacrylamide gel, and the separated peptides were transferred for immunoblotting analysis as previously described. To avoid non-specific binding of mAbs, the samples were blocked enough time (longer than $12 \mathrm{~h}$ ) and washed extensively. 
Measurement of ferroxidase activities The ferroxidase activity of CP was measured by the method of Sunderman and Nomoto (1970). Purified CP protein was incubated in $0.1 \mathrm{mM}$ sodium acetate buffer ( $\mathrm{pH} 5.7$ ) containing $0.5 \mathrm{mg} / \mathrm{ml}$ of $p$-phenylenediamine for $1 \mathrm{~h}$ at $37^{\circ} \mathrm{C}$ and the absorbance was measured at $540 \mathrm{~nm}$.

Cross reactivities of animal brains including human brain Animal brains from a cow, pig, dog, cat, rat, and chicken were removed and homogenized in a $10 \mathrm{mM}$ potassium phosphate buffer containing $0.1 \mathrm{mM}$ EDTA, $1 \mathrm{mM}$ 2-mercaptoethanol and $1 \mathrm{mM}$ PMSF. The individual $25 \%(\mathrm{w} / \mathrm{v})$ homogenates were centrifuged at $10,000 \times g$ for $1 \mathrm{~h}$. Five microliters of each supernatant were mixed with an equal volume of a $2 \times$ SDS sample buffer and boiled for 3 min. The cooled samples were applied to SDS-PAGE and transferred to nitrocellulose membranes. The blots were processed by the procedures described in Western blot. In the case of the human brain, the total proteins were prepared by homogenizing a small fragment of the cerebral cortex that was removed from a 45year old male who required surgery after an accident.

Cross reactivities among various rat organs Several rat organs, including the brain, liver, kidney, heart, lung, testes, and skeletal muscle removed and homogenized in a $10 \mathrm{mM}$ potassium phosphate buffer containing $0.1 \mathrm{mM}$ EDTA, $1 \mathrm{mM}$ 2-mercaptoethanol and $1 \mathrm{mM}$ PMSF. The individual 20\% (w/v) homogenates were centrifuged at $10,000 \times g$ for $1 \mathrm{~h}$. The samples were applied onto a $8 \%$ SDS polyacrylamide gel, and the separated peptides were transferred for immunoblotting analysis as previously described (Choi et al., 1995).

\section{Results and Discussion}

Production of monoclonal antibodies (mAbs) Human CP (CP) purified by FPLC Superose 6 chromatography formed a single band on SDS-PAGE (data not shown). To enhance its immunogenicity and to obtain antibodies with optimal reactivity on Western blots, the purified enzyme was denatured by SDS and injected into animals. From two fusion experiments, twenty positive clones were initially screened by immunodotblot analysis. Because goat anti-mouse IgG antibody was used as a secondary antibody, all of the mAbs screened by the procedure are $\mathrm{IgG}$ classes. Isotype analysis revealed that all of the $\mathrm{mAbs}$ are of the IgG $2 \mathrm{~b} \kappa$ class. For further characterization of the cell lines five hybridomas of the twenty clones were finally selected on both the reactivity and the amount of antibody secreted. The immunoreactivities of some representative mAbs with purified human $\mathrm{CP}$ are shown in Fig. 1A.

Characterization of mAbs Western blot analyses were done to characterize the specificity of the mAbs. The total proteins of the human brain were extracted, separated by SDS-PAGE, and immunoblotted with the mAbs. The antibodies specifically recognized a protein band of $130 \mathrm{kDa}$, which corresponded to the position of purified CP (Fig. 1B). The epitope recognized by mAbs were determined. mAbs
(A)

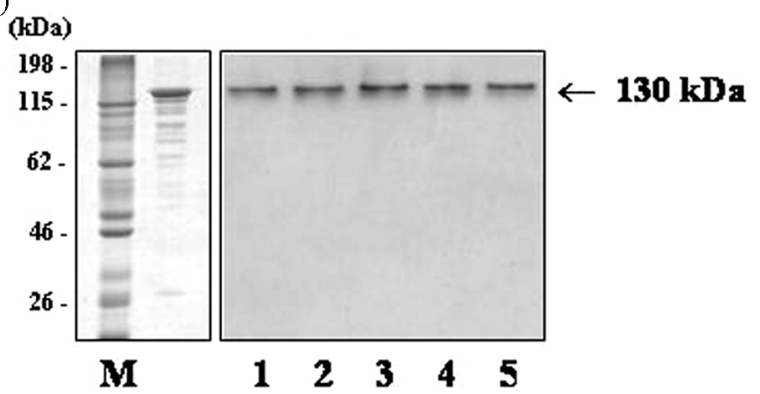

(B)

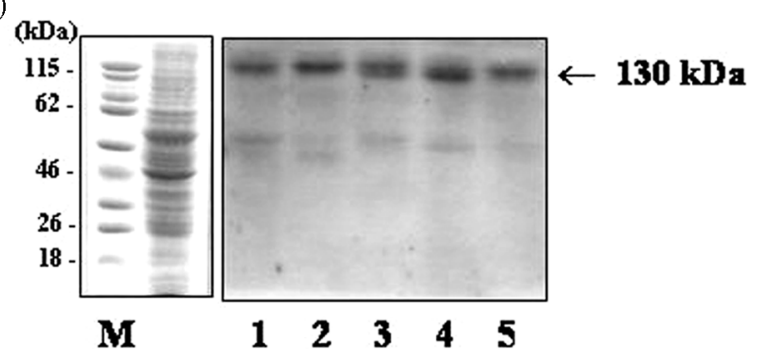

Fig. 1. SDS-PAGE and corresponding immunoblots with representative $\mathrm{CP}$ mAbs: lane 1, CP2; lane 2, CP10; lane 3, CP20; lane 4, CP25; lane 5, CP30. A: SDS-PAGE (left panel) and immunoblots of purified $\mathrm{CP}$ probed with representative mAbs in each lane (right panel). B: SDS-PAGE (left panel) and corresponding immunoblots of total proteins of rat liver homogenate (right panel). All $\mathrm{mAbs}$ specifically recognize a protein band of $130 \mathrm{kDa}$. M represents molecular mass standards.

were digested with Staphylococcus aureus V-8 protease and immunoblotted. The five mAbs can be assigned to two different groups according to their reactivities in the epitope mapping (Fig. 2). CP2, CP10, CP20, and CP25 displayed a similar staining pattern, indicating that these antibodies recognize the same or very similar epitopes. However, the mAbs CP30 showed unique band pattern.

Inhibition of $\mathbf{m A b}$ on ferroxidase activity of $\mathrm{CP}$ To determine if the mAbs can inhibit $\mathrm{CP}$ ferroxidase activity, samples of the purified CP $(2 \mu \mathrm{g})$ were incubated with the mAbs $(10 \mu \mathrm{g})$, which were purified with a protein A column. Among the five mAbs tested, three mAbs (CP2, CP10, and CP20) inhibited the enzyme activity, and the remaining activity after inhibition were $40 \%, 57 \%$ and $30 \%$, respectively. Whereas, inhibitory effect was not observed by other two mAbs (CP25 and CP30) (Fig. 3B). The dose-dependent inhibition by CP10 mAbs was further examined. After CP10 mAbs (0-5000 dilution in PBS) incubated with CP proteins, the remaining activities of $\mathrm{CP}$ were measured. Fig. $3 \mathrm{C}$ showed that the activity were inhibited dose-dependent manner. As negative control. the inhibitory effects were measured in the presence of albumin, $\operatorname{IgE}$ or $\operatorname{IgM}$, however the activities were not changed at all (data not shown). Therefore, it is suggested that the inhibitory effect by the mAbs may be due to binding at or near the active site of the $\mathrm{CP}$ protein. 


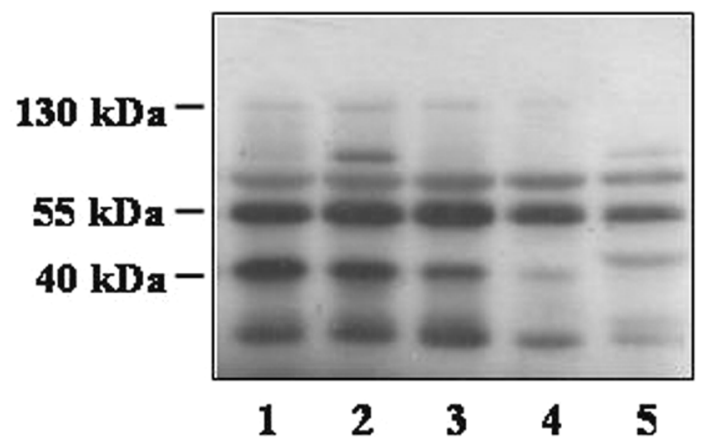

Fig. 2. Immuno-reactivity of different mAbs with purified $\mathrm{CP}$ that had been digested with Staphylococcus aureus V-8 Protease and separated by SDS-PAGE in a $8 \%$ gel. Lane 1, CP2; lane 2, CP10; lane 3, CP20; lane 4, CP25; lane 5, CP30.

It is more likely that the observed inhibitory effect involves a steric hindrance of a molecular substrate by blocking access to the active site. Alternatively, the binding of antibodies causes an inactivating, conformational changes to the protein.

\section{Cross-reactivity of the mAbs with CP from other} mammalian and avian species In order to examine the cross-reactivity of the mAbs with other mammalian and avian $\mathrm{CP}$ proteins, several animal brains from human, cow, pig, dog, cat, rat, and chicken were removed and total proteins of brain homogenate were separated, transferred and probed with the five mAbs. All five mAbs reacted with a single-protein band of $130 \mathrm{kDa}$ (Fig. 4). In the human and cow brain, mAbs showing strong reactivity than other animal brains. Although, human $\mathrm{CP}$ mAbs reactivity signals were different in other animal brain, human $\mathrm{CP}$ proteins among the mammalians share a common epitope and they seemed to be similar in protein structure. The immunoblot results in this study confirm that all mammalian $\mathrm{CP}$ enzymes are same and the subunit molecular weight may be $130 \mathrm{kDa}$. In addition, we investigated the cross-reactivity of the mAbs with various rat organs such as the brain, liver, kidney, heart, stomach, lung, testes, and skeletal muscle (Fig. 5). Total protein from the various rat tissues were extracted and immunoblotted with human CP10 mAbs. As shown in Fig. 5B, human CP mAbs strongly recognized the same protein band with $130 \mathrm{kDa}$ on the immunoblots of total proteins of some rat tissues such as brain, heart, stomach, lung and skeletal muscle. However, the band intensities of liver, kidney and testes were little bit weak. Recently, CP has been studied intensively because of its importance in physiological and pathological effects and much evidence has shown that this protein is widely distributed in various tissues. Although a rat cDNA clone encoding the CP was isolated (Fleming and Gitlin, 1990), no information is currently available on the multiplicity of the gene in mammals. Thus, it remained to be elucidate whether or not different mRNAs and/or isozymes are, in fact, expressed in a cell with a tissue specific manner. It is worthy
(A)

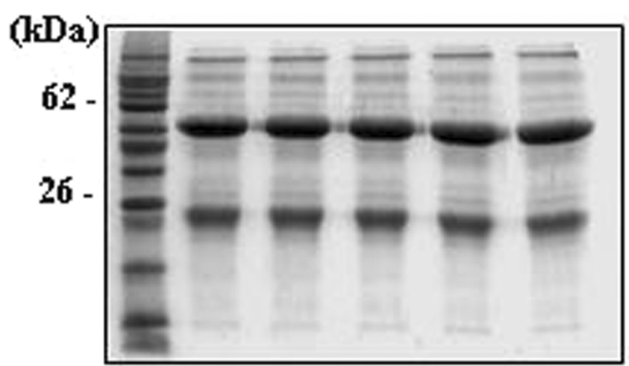

(B)

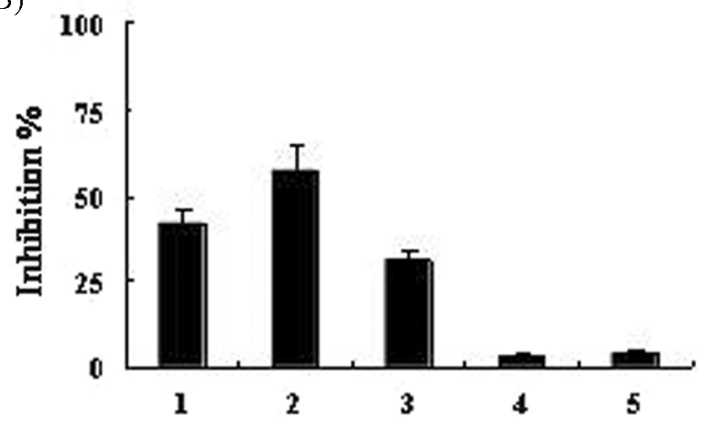

(C)

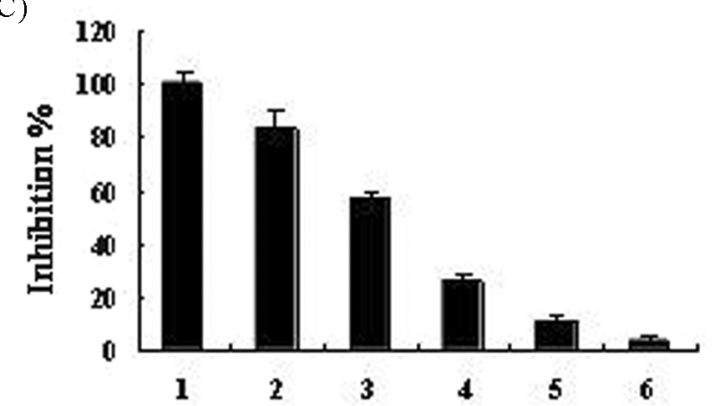

Fig. 3. An SDS-PAGE of $\mathrm{CP}$ mAbs isolated by Protein A column chromatography (A) and inhibition of $\mathrm{CP}$ activity by the purified mAbs (B): Lane 1, CP2; lane 2, CP10; lane 3, CP20; lane 4, CP25; lane 5, CP30. Samples $(2 \mu \mathrm{g}$ in $10 \mu \mathrm{l}$ of $0.1 \mathrm{M}$ photassium phosphate, $\mathrm{pH}$ 7.2) of purified human $\mathrm{CP}$ were incubated with purified mAbs $(10 \mu \mathrm{g}$ in $90 \mu \mathrm{l}$ in PBS) for $1 \mathrm{~h}$ at room temperature and the ferroxidase activity was measured using $p$-phenylenediamine as described in "Materials and Methods". (C) Dose-dependent inhibition of CP activity by the purified CP10 mAbs: Lane 1, control; lane 2, 1/200; lane 3, 1/ 500; lane 4, 1/1000, lane 5, 1/2000, lane 6, 1/5000 dilution in PBS buffer. Each bar represents the mean \pm SEM obtained four experiments.

to note that $\mathrm{CP}$ levels were increased significantly in the prostate, colon, breast, and pancreatic cancer patients as compared to normal controls (Ozyilkan et al., 2000; Nayak et al., 2003; Irigoyen Oyarzabal et al., 2003).

We also examined the immuno-reactivities in various species such as cow, cat, and dog tissues and various human cell lines (adenocarcinoma cervix HeLa3T1, macrophage J774A1, squamous carcinoma cervix SiHa, hepatomacellular carcinoma HepG2). The immuno-reactive bands of the same 
(A)

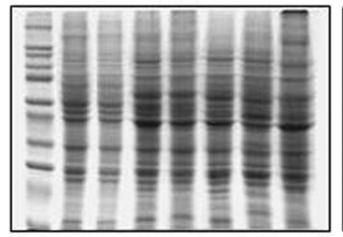

MI $12 \begin{array}{llllll}1 & 3 & 4 & 5 & 6 & 7\end{array}$
(B)

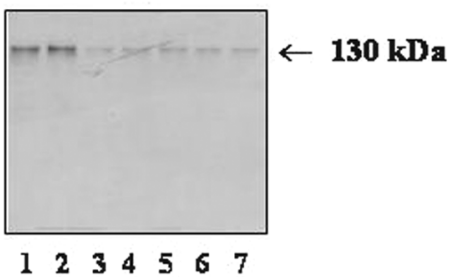

Fig. 4. Cross-reactivities of CP10 from other species with mAbs to the human protein: lane 1, human; lane 2, cow; lane 3, pig; lane 4, dog; lane 5, cat; lane 6, rat; and lane 7, chicken. Animal brains were removed, and the total proteins of the brain homogenates were immunoblotted with the CP mAbs. All of the five $\mathrm{mAbs}$ recognized the $\mathrm{CP}$ in the animal species tested. Only one immunoblot is shown. A: An SDS gel of total proteins of brain homogenates. B: Corresponding immunoblot probed with mAbs CP10.

(A)

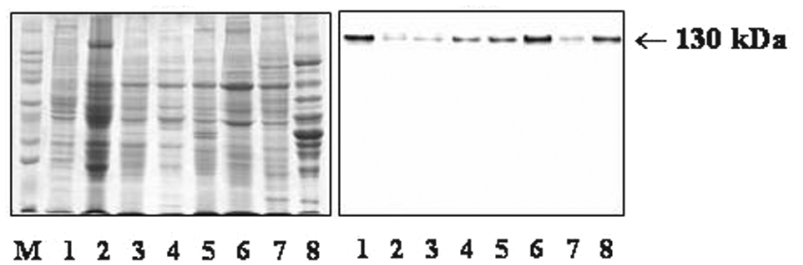

Fig. 5. SDS-PAGE (A) and immunoblot (B) of total proteins of some rat organs: lane 1, brain; lane 2, liver; lane 3, kidney; lane 4, heart; lane 5, stomach; lane 6, lung; lane 7, testes; and lane 8, skeletal muscle.

molecular mass in other animals and human cell lines tested showed the almost same patterns like rat (data not shown).

In conclusion, this study described the production and characterization of the first complete set of high-affinity monoclonal antibodies against human. Since antibodies enable the specific and sensitive detection of enzyme in tissues, they could be used for the quantitative evaluation of the proteins expression level as well as be of great benefit in extensions for immuno-histochemical study for distribution of $\mathrm{CP}$ in the brain. Furthermore, human $\mathrm{CP}$ mAbs could provide us with detection tools for monitoring diagnosis kit for $\mathrm{CP}$ related disorders including cancer and Wilson's disease.

Acknowledgments This work was supported by a Silver Biotechnology Regional Research Center Grant (R12-2002047-01002-0) from the Ministry of Science and Technology and in part by a Research Grant from the Korean Ministry of Small \& Medium Industry as well as Research Grant from Hallym University (HRF-2003-37).

\section{References}

Aouffen, M., Paquin, J., De Grandpré, E., Nadeau, R. and
Mateescu, M. A. (2001) Deglycosylated ceruloplasmin maintains its enzymatic, antioxidant, cardioprotective, and neuroprotective properties. Biochem. Cell Biol. 79, 489-497.

Choi, S. Y., Kwon, H. Y., Kwon, O. B., Eum, W. S. and Kang, J. H. (2000) Fragmentation of human ceruloplasmin induced by hydrogen peroxide. Biochimie 82, 175-180.

Choi, E. Y., Park, S. Y., Jang, S. H., Song, M. S., Cho, S. W. and Choi, S. Y. (1995) Production and characterization of monoclonal antibodies to bovine brain succinic semialdehyde reductase. J. Neurochem. 64, 371-377.

Choi, E. Y., Jang, S. H. and Choi, S. Y. (1996) Human brain GABA transaminase is immunologically distinct from those of other mammalian brain. Neurochem. Int. 28, 597-600.

Culotta, V. C. and Gitlin, J. D. (2001) Disorders of copper transport; in The Metabolic Basis of Inheritd Disease, Scrier, C. R., Beaudet, A. L., Sly, W. S. and Valle, D. (eds.), pp. 3105-3126, McGraw Hill, New York, USA.

Danks, D. M. (1989) Disorders of copper transport; in The Metabolic Basis of Inheritd Disease, Scrier, C. R., Beaudet, A. L., Sly, W. S. and Valle, D. (eds.), pp. 1411-1431, McGraw Hill, New York, USA.

Eum, W. S. and Kang, J. H. (1999) Release of copper ions from the familial amyotrophic lateral sclerosis-associated $\mathrm{Cu}, \mathrm{Zn}$ superoxide dismutase mutants. Mol. Cells 9, 110-114.

Fleming, R. E. and Gitlin, J. D. (1990) Primary structure of rat ceruloplasmin and analysis of tissue-specific gene expression during development. J. Biol. Chem. 265, 7701-7707.

Fleming, R. E., Whitman, I. P. and Gitlin, J. D. (1991) Induction of ceruloplasmin gene expression in rat lung during inflammation and hyperoxida. Am. J. Physiol. 260, 68-74.

Gitlin, J. D. (1988) Transcriptional regulation of ceruloplasmin gene expression during inflammation. J. Biol. Chem. 263, 6281-6287.

Irigoyen Oyarzabal, A. M., Amiguet Garicia, J. A., Lopez Vivaco, G., Genolla Subirats, J., Munoz Villafranca, M. C., Ojembarrena Martinez, E. and Liso Irurzun, P. (2003) Tumoral markers and acute-phase reactants in the diagnosis of pancreatic cancer. Gastroenterol. Hepatol. 26, 624-629.

Kang, J. H., Kim, K. S., Choi, S. Y., Kwon, H. Y., Won, M. H. and Kang, T. C. (2002) Protection by carnosine-related dipeptides against hydrogen peroxide-mediated ceruloplasmin modification. Mol. Cells 13, 107-112.

Lee, H. Y., Eum, W. S., Kim, D. W., Lee, B. R., Yoon, C. S., Jang, S. H., Choi, H. S., Choi, S. H., Back, N.-I., Kang, J. H., Kang, T.-C., Won, M. H., Cho, S.-W., Lee, K. S., Park, J. and Choi, S. Y. (2003) Isolation and identification of antioxidant enzyme catalase stimulatory compound from Garnoderma lucidum. J. Biochem. Mol. Biol. 36, 450-455.

Lee, Y. and Song, K. B. (2002) Effects of $\gamma$-irradiation on the molecular properties of myoglobin. J. Biochem. Mol. Biol. 35, 590-594.

Mateescu, M. A., Chahine, R., Roger, S., Atanasiu, R., Yamaguchi, N., Nalumiére, G. and Nadeau, R. (1995) Protection of myocardial tissue against deleterious effects of oxygen free radicals by ceruloplasmin. Arzneim.-Forsch. 45, 476-480.

Nayak, S. B., Bhat, V. R., Upadhyay, D. and Udupa, S. L. (2003) Copper and ceruloplasmin status in serum of prostate and colon cancer patients. Indian J. Physiol. Pharmacol. 47, 108110. 
Osaki, S., Johnson, D. A. and Frieden, E. (1966) The possible significance of the ferrous oxidase activity of ceruloplasmin in normal human serum. J. Biol. Chem. 241, 2746-2751.

Ozyilkan, O., Baltali, E. and Kirazli, S. (2000) CA 15-3, ceruloplasmin and tissue polypeptide specific antigen as a tumour marker panel in breast cancer. East Afr. Med. J. 77, 291-294.

Richardson, D. R. (1999) Role of ceruloplasmin and ascorbate in cellular iron release. J. Lab. Clin. Med. 13, 454-465.

Scheinberg, I. H. and Steinlieb, I. (1984) Ceruloplasmin; in Wilson Disease, Lloyd, H. and Smith, Jr. (eds.), pp. 1-171, W. B.
Saunders Co., Philadelphia, USA.

Shulman, H., Wilde, C. D. and Kohler, G. (1978) A better cell line for making hybridomas secreting specific antibodies, Nature 276, 269-270.

Sunderman, F. W. Jr. and Nomoto, S. (1970) Measurement of human serum ceruloplasmin by its $p$-phenylenediamine oxidase activity. Clin. Chem. 16, 903-910.

Swain, J. A., Darley-Usmar, V. and Gutteridge, J. M. (1994) Peroxynitrite release copper from ceruloplasmin: implications for atherosclerosis. FEBS Lett. 342, 49-52. 